\title{
Cancer Antigen 1 Measurement
}

National Cancer Institute

\section{Source}

National Cancer Institute. Cancer Antigen 1 Measurement. NCI Thesaurus. Code C103361.

The determination of the amount of the cancer antigen 1 in a sample. 